\title{
EL ESTADO DE ALARMA: DESDE EL ORIGEN AL COVID-19*
}

\author{
Miguel Ángel PRESNO LiNERA \\ Catedrático de Derecho Constitucional \\ Departamento de Derecho Público \\ Facultad de Derecho. Universidad de Oviedo \\ presno@uniovi.es
}

\begin{abstract}
A las miles de personas que están trabajando de forma ejemplar durante esta pandemia y que han mantenido siempre encendida la luz al final del túnel.
\end{abstract}

\begin{abstract}
RESUMEN
Como es sabido, el pasado 14 de marzo de 2020 se declaró el estado de alarma por segunda vez en la reciente historia constitucional española. En este texto se analiza el origen y el desarrollo legislativo del estado de alarma, la declaración de este estado en 2010 para resolver el caos creado por la buelga de controladores aéreos y la reciente declaración para hacer frente a la crisis sanitaria causada por el Covid-19. Finalmente, se reflexiona sobre el estado de alarma en la llamada sociedad del riesgo global.

Palabras clave: Estado de alarma, derechos fundamentales, Covid-19, confinamiento, sociedad del riesgo.
\end{abstract}

\section{ABSTRACT}

It is well known that last March 14th 2020 a State of Alarm was called for the second time in recent Spanish history. We bereby look into the declaration and follow up of such State of Alarm, the previous State of Alarm called in 2010 in order to

*presnolinera@gmail.com; http://presnolinera.wix.com/presnolinera. Me he ocupado de estas cuestiones en «Estado de alarma por coronavirus y protección jurídica de los grupos vulnerables», El Cronista del Estado Social y Democrático de Derecho, núm. 86-87 (2020), pp. 54-65; «Coronavirus SARS-CoV-2, garantía de derechos fundamentales y límites a los mismos en el Derecho español», en BLJ 2/20: Instant Forum-Diritto, diritti ed emergenza ai tempi del Coronavirus, 2020, disponible en https://www.biodiritto.org/Online-First-BLJ/ Online-First-BLJ-2-20-Instant-Forum-Diritto-diritti-ed-emergenza-ai-tempi-del-Coronavirus, y «Estado de alarma y sociedad del riesgo global», en J. F. Rodríguez Ayuso y E. AtienZA Macías (coords.), Las respuestas del Derecho a las crisis de salud pública, Madrid, Dykinson, 2020, pp. 15-28 (en prensa). En bttp://presnolinera.wordpress.com he venido publicando diversas entradas sobre esta cuestión desde el 9 de marzo; en el proyecto bttp://derechocovid.com, «Observatorio de Derecho Público y Constitucional y Covid-19 en España», se puede consultar una amplísima bibliografía. 
solve the chaos following air controllers strikes and the current State of Alarm to face Covid-19's healthcare system crisis. We will finally reflect on a State of Alarm in a so-called global risk society.

Keywords: State of Alarm, Fundamental Rights, Covid-19, Lockdown, Risk Society.

\section{ZUSAMMENFASSUNG}

Wie bekannt, wurde am 14. März 2020 zum zweiten Mal in der jüngeren Verfassungsgeschichte Spaniens der Alarmzustand ausgerufen. Dieser Text analysiert den Ursprung und die gesetzgeberische Entwicklung des Alarmzustands, die Ausrufung dieses Zustands im Jahr 2010, um das durch den Fluglotsenstreik verursachte Chaos zu beheben, und die jüngste Ausrufung, um mit der durch Covid-19 verursachten Gesundheitskrise umzugehen. Abschließend reflektiert er den Alarmzustand der sogenannten globalen Risikogesellschaft.

Schlüsselwörter: Alarmzustand, Grundrechte, Covid-19, Ausgangssperre, Risikogesellschaft.

SUMARIO: I. APROXIMACIÓN AL ORIGEN Y AL DESARROLLO DEL ESTADO DE ALARMA EN ESPAÑA.-II. LA PRIMERA DECLARACIÓN DEL ESTADO DE ALARMA (EL REAL DECRETO 1673/2010, DE 4 DE DICIEMBRE, POR EL QUE SE DECLARA EL ESTADO DE ALARMA PARA LA NORMALIZACIÓN DEL SERVICIO PÚBLICO ESENCIAL DEL TRANSPORTE AÉREO) Y SU DUDOSA LEGALIDAD.-III. LA DECLARACIÓN DEL ESTADO DE ALARMA POR EL REAL DECRETO 463/2020, DE 14 DE MARZO, POR EL QUE SE DECLARA EL ESTADO DE ALARMA PARA LA GESTIÓN DE LA SITUACIÓN DE CRISIS SANITARIA OCASIONADA POR EL COVID-19, Y LAS SUCESIVAS PRÓRROGAS.-IV. BREVÍSIMO EPÍLOGO: LA NECESARIA REFLEXIÓN SOBRE EL ESTADO DE ALARMA EN LA SOCIEDAD DEL RIESGO GLOBAL.-V. REFERENCIAS BIBLIOGRÁFICAS.

\section{APROXIMACIÓN AL ORIGEN Y AL DESARROLLO DEL ESTADO DE ALARMA EN ESPAÑA}

Es bien sabido que en 1981 tuvo lugar en España el intento de golpe de Estado del 23 de febrero; pocos meses después de este fracasado proyecto de derribar la democracia se publicó la Ley Orgánica 4/1981, de 1 de junio, de los Estados de Alarma, Excepción y Sitio, que desarrolla el art. 116 de la Constitución española (CE), no especialmente concreto en lo que respecta al estado de alarma ${ }^{1}$.

${ }^{1}$ «1. Una ley orgánica regulará los estados de alarma, de excepción y de sitio, y las competencias y limitaciones correspondientes. 
La Ley Orgánica 4/1981 había empezado su andadura parlamentaria en septiembre de 1979 bajo una forma bien diferente: como proyecto de ley orgánica de seguridad ciudadana que, según su memoria/preámbulo, suponía «un importante cambio en relación con la Ley de Orden Público de 1959 y criterios inspiradores de la misma, al conjugar la nueva normativa la defensa de las instituciones con el fortalecimiento de los sistemas de garantía de las libertades públicas». Dentro de este proyecto de ley, el capítulo III era el dedicado a la regulación de los estados de alarma, excepción y sitio, dando cumplimiento, según la memoria, «a lo dispuesto en el art. 116 de la Constitución, según el cual una ley orgánica regulará los estados de alarma, excepción y sitio, determinando las competencias y los procedimientos para la declaración de cada uno de los tres estados y previendo la incidencia de los mismos en las relaciones entre el Gobierno y el Congreso de los Diputados». Insiste el precepto citado en la exigencia de concretar los efectos de las respectivas declaraciones, lo que constituye una clara referencia, por lo que respecta a los estados de excepción y sitio, al art. 55 de la propia Constitución, cuyo párrafo 1 determina expresamente, por vía enumerativa y con carácter excluyente, los derechos fundamentales y las libertades públicas que podrán ser suspendidos cuando se produzca la declaración de dichos estados.

2. El estado de alarma será declarado por el Gobierno mediante decreto acordado en Consejo de Ministros por un plazo máximo de quince días, dando cuenta al Congreso de los Diputados, reunido inmediatamente al efecto y sin cuya autorización no podrá ser prorrogado dicho plazo. El decreto determinará el ámbito territorial a que se extienden los efectos de la declaración.

3. El estado de excepción será declarado por el Gobierno mediante decreto acordado en Consejo de Ministros, previa autorización del Congreso de los Diputados. La autorización y proclamación del estado de excepción deberá determinar expresamente los efectos del mismo, el ámbito territorial a que se extiende y su duración, que no podrá exceder de treinta días, prorrogables por otro plazo igual, con los mismos requisitos.

4. El estado de sitio será declarado por la mayoría absoluta del Congreso de los Diputados, a propuesta exclusiva del Gobierno. El Congreso determinará su ámbito territorial, duración y condiciones.

5. No podrá procederse a la disolución del Congreso mientras estén declarados algunos de los estados comprendidos en el presente artículo, quedando automáticamente convocadas las Cámaras si no estuvieren en periodo de sesiones. Su funcionamiento, así como el de los demás poderes constitucionales del Estado, no podrán interrumpirse durante la vigencia de estos estados.

Disuelto el Congreso o expirado su mandato, si se produjere alguna de las situaciones que dan lugar a cualquiera de dichos estados, las competencias del Congreso serán asumidas por su Diputación Permanente.

6. La declaración de los estados de alarma, de excepción y de sitio no modificarán el principio de responsabilidad del Gobierno y de sus agentes reconocidos en la Constitución y en las leyes». 
Sin embargo, aunque la Constitución española, frente al criterio mantenido por otros textos constitucionales recientes — como la Ley Federal de Bonn o la Constitución italiana de 1947-, haya seguido la línea de recoger en su propio articulado los mecanismos de defensa extraordinarios de las instituciones públicas y a pesar de que, como elemento equilibrante o compensador, haya sido muy precisa y minuciosa en la determinación de las competencias y procedimientos para la declaración de los estados de alarma, excepción y sitio, ha sido realmente sobria en la definición de los conceptos y en la concreción del contenido de los tres estados extraordinarios, respecto a los cuales apenas hace otra cosa que mencionar sus nombres.

Nos referiremos al contenido de este proyecto legislativo únicamente en lo relativo al estado de alarma, pues sirve para constatar el notable cambio que experimentó a lo largo de su tramitación parlamentaria y que tiene mucho que ver con el alcance que puede tener la declaración de ese estado con motivo de la pandemia de Covid-19 en el mes de marzo de 2020.

Dice la memoria del proyecto en relación con la terminología y el pretendido alcance del estado de alarma lo siguiente: «La denominación del estado de alarma, aunque coincidente con una de las usadas en la Ley de Orden Público de 28 de julio de 1933, responde ahora a una realidad distinta: el estado de alarma de la ley republicana es homólogo propiamente del estado de excepción, según la concepción de la Ley de 1959 y según el proyecto que ahora se presenta». El proyecto, en su concepción del estado de alarma, sigue muy de cerca al Proyecto de Ley de Modificación de la Ley de Orden Público, tramitado durante el pasado año, recogiendo, en la enumeración de los supuestos determinantes de su declaración, además de las alteraciones del orden público: las catástrofes, calamidades o desgracias públicas; epidemias o situaciones de contaminación grave; paralización de servicios públicos esenciales, y situaciones de desabastecimiento de productos de primera necesidad.

Se trata fundamentalmente de eventos en los que peligra la seguridad o la salud de las personas, o se encuentra en riesgo grave el mantenimiento de las condiciones físicas necesarias para el desenvolvimiento de la vida de la colectividad.

Por ello, el conjunto de medidas para cuya adopción se faculta a las autoridades gubernativas, aparte de la lógica concentración de atribuciones administrativas, tiende, de una parte, con carácter positivo, a la movilización de personas y recursos materiales para asegurar la protección, asistencia y seguridad de las personas, bienes y lugares afectados, y, de otra, 
con carácter negativo, a controlar o limitar, con la misma finalidad, el movimiento de personas y vehículos y el consumo de artículos o servicios de primera necesidad.

El proyecto respeta, pues, escrupulosamente el art. 55.1 de la Constitución, que al regular la suspensión de los derechos y libertades se refiere expresamente a los estados de excepción y sitio, pero no menciona para nada el estado de alarma.

Ya en el articulado del proyecto se incluían los supuestos que podrían dar lugar a la declaración del estado de alarma:

«El Gobierno, en uso de las facultades que le otorga el apartado 2 del art. 116 de la Constitución, podrá declarar el estado de alarma en todo o parte del territorio nacional cuando concurran situaciones como las siguientes:

a) Alteraciones del orden o de la seguridad ciudadana cuando su restablecimiento no se pueda conseguir mediante el uso de las potestades ordinarias de la autoridad gubernativa.

b) Catástrofes, calamidades o desgracias públicas, tales como terremotos, inundaciones, incendios urbanos y forestales o accidentes de gran magnitud.

c) Crisis sanitarias, tales como estados epidémicos y situaciones de contaminación grave.

d) Paralización de servicios públicos esenciales.

e) Situaciones de desabastecimiento de productos de primera necesidad».

Basta recordar ahora que en el informe de la ponencia al paso del proyecto de ley por el Congreso de los Diputados, publicado el 20 de octubre de 1980, se propuso el desglose en cuatro proyectos de ley distintos, uno de ellos relativo a los estados de alarma, excepción y sitio. Y el siguiente hito parlamentario lo encontramos ya en el Dictamen de la Comisión Constitucional del Congreso sobre la «Ley Orgánica de los Estados de Alarma, Excepción y Sitio», publicado en el Boletín de la Cámara el 14 de abril de 1981. En este informe ya ha desaparecido la letra a) del proyecto originario, que era la que contemplaba la declaración del estado de alarma ante «alteraciones del orden o de la seguridad ciudadana cuando su restablecimiento no se pueda conseguir mediante el uso de las potestades ordinarias de la autoridad gubernativa». De esta forma se desvincula el estado de alarma de la cuestión del orden público y así se propone en el Dictamen de la Comisión de la misma fecha, 
aunque se mantiene el carácter ejemplificativo de los supuestos: «cuando concurran situaciones como las siguientes».

Será en el Pleno del Congreso de 23 de abril de 1981 cuando las causas ejemplificativas pasan a ser taxativas y el texto adquiere la redacción que hoy sigue vigente:

«El Gobierno, en uso de las facultades que le otorga el art. 116.2 de la Constitución, podrá declarar el estado de alarma en todo o parte del territorio nacional cuando se produzca alguna de las siguientes alteraciones graves de la normalidad:

a) Catástrofes, calamidades o desgracias públicas, tales como terremotos, inundaciones, incendios urbanos y forestales o accidentes de gran magnitud.

b) Crisis sanitarias, tales como epidemias y situaciones de contaminación graves.

c) Paralización de servicios públicos esenciales para la comunidad cuando no se garantice lo dispuesto en los arts. 28.2 y 37.2 de la Constitución y concurra alguna de las demás circunstancias o situaciones contenidas en este artículo.

d) Situaciones de desabastecimiento de productos de primera necesidad».

Pues bien, de la lectura conjunta del párrafo anterior resulta que hay tres situaciones que justifican de por sí la adopción del estado de alarma (puntos 1, 2 y 4) y otra (la 3) que se vincula a las anteriores («concurra alguna de las demás circunstancias o situaciones contenidas en este artículo) y eso implica, por tanto, que la paralización de servicios esenciales para la comunidad sin garantizar lo previsto en el art. 28.2 (derecho de huelga) y 37.2 (medidas de conflicto colectivo), es decir, sin asegurar el mantenimiento de los servicios esenciales de la comunidad (por ejemplo, el sanitario o el del transporte), debe producirse en una situación, por ejemplo, de crisis sanitaria, tal como una epidemia.

No cabe, por tanto, la declaración del estado de alarma en el contexto de un problema de orden público y ello porque, como explica el profesor Cruz Villalón, el legislador efectuó una «despolitización» del estado de alarma, dejándolo al margen de las situaciones de desorden público o conflictividad social, para destinarlo a combatir las catástrofes naturales o tecnológicas (añadiríamos nosotros sanitarias) ${ }^{2}$.

2 P. CRuZ Villalón, «El nuevo derecho de excepción (Ley Orgánica 4/1981, de 1 de junio)», Revista Española de Derecho Constitucional, núm. 2 (1981), pp. 93-128, e íD., Esta- 
De hecho, en la Ley Orgánica 4/1981 no se habla de «orden público» hasta que no se llega al estado de excepción y ello implica que no hay un paso intermedio — estado de alarma- entre el «orden» y el «desorden» públicos, sino que se pasa directamente de la situación de normalidad al estado de excepción, sin que quepan situaciones intermedias más o menos ambiguas. Dispone al respecto el art. 13 de la Ley Orgánica 4/1981: «Cuando el libre ejercicio de los derechos y libertades de los ciudadanos, el normal funcionamiento de las instituciones democráticas, el de los servicios públicos esenciales para la comunidad o cualquier otro aspecto del orden público resulten tan gravemente alterados que el ejercicio de las potestades ordinarias fuera insuficiente para restablecerlo y mantenerlo, el Gobierno, de acuerdo con el apartado tres del artículo ciento dieciséis de la Constitución, podrá solicitar del Congreso de los Diputados autorización para declarar el estado de excepción» (la cursiva es nuestra).

En esta misma línea pueden recordarse las palabras, durante su intervención parlamentaria, del entonces senador Fernando Morán, recientemente fallecido: «No se trata de etapas, de escalas en una escalera con intensidad diferente del mismo proceso; se trata de situaciones cualitativamente distintas: el estado de alarma para unas situaciones que vienen de hechos naturales o sociales que ocurren en la historia; el estado de excepción para situaciones que afectan al orden público y que es previsible que

dos excepcionales y suspensión de garantías, Madrid, Tecnos, 1984. Vid. también F. FERNÁNDEZ SEgADO, «La ley orgánica de los estados de alarma, excepción y sitio», Revista de Derecho Político, núm. 11 (1981), pp. 83-116; D. López Garrido, Estados de alarma, excepción y sitio. Trabajos parlamentarios, Madrid, Cortes Generales, 1984; A. CARRO MarTíneZ, «Art. 116. Situaciones de anormalidad constitucional», en Ó. Alzaga VillaMIL (dir.), Comentarios a la Constitución española de 1978, Madrid, Edersa, 1998, pp. 210 y ss.; I. Torres Muro, «Art. 116. Los estados excepcionales», en M. E. CASAS BAAMONDE y M. Rodríguez-Piñero y Bravo-FerRer (dirs.), Comentarios a la Constitución española. XXX aniversario, Madrid, Wolters Kluwer, 2009, pp. 1814 y ss.; A. AвA CATOIRA, «El estado de alarma en España», Teoría y Realidad Constitucional, núm. 28 (2011), pp. 305-334; P. Requejo RodrígueZ, «Teoría y práctica del estado de alarma en España», y N. PéreZ SolA, «Los estados de alarma, excepción y sitio: la primera declaración del estado de alarma en aplicación de las previsiones constitucionales», ambos en Constitución y democracia. Ayer y hoy: libro bomenaje a Antonio Torres del Moral, vol. 2, Madrid, Universitas, 2012, pp. 1499-1514 y 1539-1556, respectivamente, y C. GARRIDO LÓPEZ, «Naturaleza jurídica y control jurisdiccional de las decisiones constitucionales de excepción», Revista Española de Derecho Constitucional, núm. 110 (2017), pp. 43-73. Asimismo, vid. P. Requejo Rodríguez, «¿Suspensión o supresión de los derechos fundamentales?», Revista de Derecho Político, núm. 51 (2001), pp. 105 y ss., e ÍD., «Art. 55. De la suspensión de los derechos y libertades», en M. E. Casas BaAmonde y M. Rodríguez-Piñero y Bravo-Ferrer (dirs.), Comentarios a la Constitución española. XXX aniversario, Madrid, Wolters Kluwer, 2009, pp. 1201 y ss. 
no puedan atajarse por los medios ordinarios, y el estado de sitio ante procesos que afecten al orden constitucional» ${ }^{3}$.

\section{LA PRIMERA DECLARACIÓN DEL ESTADO DE ALARMA (EL REAL DECRETO 1673/2010, DE 4 DE DICIEMBRE, POR EL QUE SE DECLARA EL ESTADO DE ALARMA PARA LA NORMALIZACIÓN DEL SERVICIO PÚBLICO ESENCIAL DEL TRANSPORTE AÉREO) Y SU DUDOSA LEGALIDAD}

Como se recordará, el 4 de diciembre de 2010 se acudió, por vez primera en la reciente historia constitucional española, a la declaración del estado de alarma previsto, como ya se ha dicho, en el art. 116 CE y desarrollado por la LO 4/1981. Según el preámbulo del Real Decreto 1673/20104:

«Las circunstancias extraordinarias que concurren por el cierre del espacio aéreo español como consecuencia de la situación desencadenada

3 Diario de Sesiones del Senado, núm. 105 (1981), disponible en bttp://www.congreso. es/public_oficiales/L1/SEN/DS/PL/PS0105.PDF (consultado el 14 de mayo de 2020).

${ }^{4} \mathrm{El}$ articulado fue el siguiente:

«Artículo 1. Declaración del estado de alarma. Al amparo de lo dispuesto en el art. 4, apartado $c$ ), en relación con los apartados a) y d) de la Ley Orgánica 4/1981, de 1 de junio, de los Estados de Alarma, Excepción y Sitio, se declara el estado de alarma con el fin de afrontar la situación de paralización del servicio público esencial del transporte aéreo.

Artículo 2. Ámbito territorial y material. La declaración de estado de alarma afecta, en todo el territorio nacional, a la totalidad de las torres de control de los aeropuertos de la red y a los centros de control gestionados por la entidad pública empresarial "Aeropuertos Españoles y Navegación Aérea (AENA)".

Artículo 3. Ambito subjetivo. En virtud de lo dispuesto en los arts. 9.uno y 12.dos de la Ley Orgánica 4/1981 en relación con el art. 44 de la Ley 48/1960, de 21 de julio, sobre Navegación Aérea, todos los controladores de tránsito aéreo al servicio de AENA pasan a tener, durante la vigencia del estado de alarma, la consideración de personal militar a los efectos de lo previsto en el art. 10.uno de la citada ley orgánica y, en consecuencia, quedan sometidos a las órdenes directas de las autoridades designadas en el presente real decreto y a las leyes penales y disciplinarias militares, de conformidad con lo dispuesto en el art. 8.5 de la Ley Orgánica 13/1985, de 9 de diciembre.

Artículo 4. Licencias, habilitaciones y anotaciones. Los controladores civiles de tránsito aéreo al servicio de AENA mantendrán todas las facultades inherentes a las licencias, habilitaciones, anotaciones y certificados médicos de que sean titulares, si bien ejercerán dichas atribuciones, en todo caso, bajo la organización y supervisión del Ejército del Aire.

Artículo 5. Duración. La duración del estado de alarma que se declara en este real decreto es de quince días naturales.

Artículo 6. Autoridad delegada del Gobierno. El jefe de Estado Mayor del Ejército del Aire y las autoridades militares que designe adoptarán las decisiones pertinentes en cumplimiento de lo que dispone el art. 3 del presente real decreto». 
por el abandono de sus obligaciones por parte de los controladores civiles de tránsito aéreo impiden el ejercicio del derecho fundamental mencionado y determinan la paralización de un servicio público esencial para la sociedad como lo es el servicio de transporte aéreo. Todo ello constituye, sin duda, una calamidad pública de enorme magnitud por el muy elevado número de ciudadanos afectados, la entidad de los derechos conculcados y la gravedad de los perjuicios causados.

Para recuperar la normalidad en la prestación del citado servicio público y restablecer los derechos fundamentales de los ciudadanos, hoy menoscabados, y habiendo fracasado todos los intentos para poner fin a la situación de catástrofe pública existente, es indispensable proceder a la declaración del estado de alarma en orden a eliminar los obstáculos que impiden su segura y continuada prestación»s.

No nos extenderemos en el análisis de este primer estado de alarma (véase la bibliografía citada), pero sí parece oportuno comentar, al menos, una cuestión que servirá para delimitar el marco más general de la configuración del estado de alarma en nuestro ordenamiento: la de las causas que justifican su declaración.

Como se ha visto, en el preámbulo se invoca, como argumento que avalaría la medida que se adopta, «el cierre del espacio aéreo español como consecuencia de la situación desencadenada por el abandono de sus obligaciones por parte de los controladores civiles de tránsito aéreo, impiden el ejercicio del derecho fundamental mencionado y determinan la paralización de un servicio público esencial para la sociedad como lo es el servicio de transporte aéreo» (la cursiva es nuestra). Este supuesto de hecho encaja, sin problemas aparentes, en la primera parte de la causa prevista en la letra $c$ ) del art. 4 de la LO 4/1981: «c) Paralización de servicios públicos esenciales para la comunidad (el transporte aéreo), cuando no se garantice lo dispuesto en los arts. 28.2 y 37.2 de la Constitución», aunque parece un exceso justificativo apelar a que se está impidiendo el ejercicio del derecho fundamental a la libertad de circulación, pues, en el peor de los casos,

${ }^{5}$ Una descripción en profundidad del origen y evolución del conflicto al que se pretendió dar respuesta con el estado de alarma puede encontrarse en el estudio de C. VIDAL Prado y D. Delgado Ramos, «Algunas consideraciones sobre la declaración del estado de alarma y su prórroga», Revista Española de Derecho Constitucional, núm. 92 (2011), pp. 244 y ss. Vid. también F. J. Enérez OlaecheA, «La declaración del estado de alarma para la normalización del transporte aéreo», Revista Aranzadi Doctrinal, núm. 6 (2011), pp. 79-94, y los ya citados trabajos de A. Aba CATOIRA, «El estado de alarma...», op. cit..; P. REQuejo RodríGUEZ, «Teoría y práctica del estado de alarma...», op. cit., y N. PÉrez SolA, «Los estados de alarma, excepción y sitio...», op. cit. 
no se podía llevar a cabo por un medio concreto —el transporte aéreo-, pero en nada quedaron afectados otros medios de transporte que sí permitían ejercer la libertad de circulación dentro del territorio nacional, que es lo protegido por el art. $19 \mathrm{CE}$.

En todo caso, y como ya se ha dicho, con eso no sería suficiente, pues la citada letra añade «y concurra alguna de las demás circunstancias o situaciones contenidas en este artículo». A tratar de colmar esta exigencia se encaminan otras frases del preámbulo: «Todo ello constituye, sin duda, una calamidad pública de enorme magnitud por el muy elevado número de ciudadanos afectados, la entidad de los derechos conculcados y la gravedad de los perjuicios causados [...] habiendo fracasado todos los intentos para poner fin a la situación de catástrofe pública existente, es indispensable proceder a la declaración del estado de alarma en orden a eliminar los obstáculos que impiden su segura y continuada prestación» (las cursivas son nuestras).

Como se recordará, la letra a) del mismo art. 4 habla, expresamente, de «catástrofes, calamidades o desgracias públicas», aunque de inmediato ejemplifica y menciona: «terremotos, inundaciones, incendios urbanos y forestales o accidentes de gran magnitud».

Nos parece que la paralización del tráfico aéreo no encaja en el tipo de catástrofes o calamidades a las que se refiere esa letra e, incluso, que quepa calificarla como una auténtica catástrofe en los términos jurídicos en los que parece estar pensando la ley reguladora. En palabras del Tribunal Constitucional: «El art. 4 de la Ley Orgánica 4/1981 identifica las situaciones de emergencia o, en sus propios términos, las "alteraciones graves de la normalidad" que pueden dar lugar a su declaración, referidas, en síntesis, a emergencias naturales o tecnológicas, a crisis sanitarias, a situaciones de desabastecimiento de productos de primera necesidad y/o a la paralización de servicios públicos esenciales para la comunidad, cuando no se garanticen los servicios mínimos (arts. 28.2 y 37.2 CE) y además concurra, respecto a este último supuesto, alguna de las otras situaciones definidas en el precepto» (STC 83/2016, de 28 de abril, FJ 8).

Por todo ello, no considero exagerado calificar al Decreto 1673/2010 de ilegal, como hacen, por ejemplo, Vidal Prado y Delgado Ramos ${ }^{6}$. Y lo que me parece más relevante en términos generales es que esta pri-

\footnotetext{
${ }^{6}$ C. Vidal Prado y D. Delgado Ramos, «Algunas consideraciones sobre la declaración...», op. cit., p. 254.
} 
mera declaración del estado de alarma evidenció las limitaciones de la LO 4/1981, pero en casi diez años no se ha hecho nada por colmarlas ${ }^{7}$.

Una cuestión adicional que se suscitó con ocasión del Decreto 1673/2010 fue la de su control jurisdiccional: si partimos de que la declaración del estado de alarma se realiza mediante decreto del Consejo de Ministros no parecería descabellado entender que cabe un control de su legalidad por la Sala de lo Contencioso-Administrativo del Tribunal Supremo (en adelante, TS); sin embargo, esta vía fue descartada de raíz por el propio Supremo con ocasión de los recursos presentados por los controladores aéreos: en siete autos dictados entre 2011 y 2012 (AATS 857/2011, de 10 de febrero; 2985/2011, de 9 de marzo; 3816/2011, de 5 de abril; 5696/2011 y 5698/2011, de 30 de mayo; 6821/2011, de 8 de junio, y 6197/2012, de 1 de junio) el Supremo estimó que la declaración del estado de alarma no es un ejercicio de la potestad reglamentaria que le atribuye al Gobierno el art. $96 \mathrm{CE}$, sino de la competencia constitucional, diferente, regulada en el art. 116.2 CE.

Esta doctrina fue asumida por el Tribunal Constitucional (en adelante, TC), primero por mayoría (Auto 7/2012, de 13 de enero) y luego por unanimidad (STC 83/2016, de 28 de abril), al entender que, aunque formalizada mediante decreto del Consejo de Ministros, la decisión de declarar el estado de alarma, dado su contenido normativo y efectos jurídicos, queda configurada en nuestro ordenamiento como una decisión o disposición con rango o valor de ley ${ }^{8}$.

Y a esta doctrina se acogerá, en su Auto de 4 de mayo de 2020, el Tribunal Supremo al resolver el recurso en el que, en forma directa, «se impugna el Real Decreto 463/2020, de 14 de marzo, por el que se declara el estado de alarma para gestión de la pandemia ocasionada por infección del acrónimo Covid-19, así como el Real Decreto 476/2020, de 27 de marzo; el Real Decreto 4870/2020, de 10 de abril, y el Real Decreto 463/2020, que establecen sus prórrogas, así como - en lo que se denomina ampliación- el Real Decreto 492/2020, de 24 de abril, que lo prorroga por tercera vez».

Este auto, que recuerda la anterior jurisprudencia tanto del TS como del TC, insiste (FJ 4) en que «la posibilidad de control en estos casos

7 Para Cruz Villalón la letra $c$ ) del art. 4 es, en realidad, un «no-supuesto», pues la adición del requisito final equivale a la supresión del propio supuesto. Vid. P. CRUZ VILlalón, Estados excepcionales y suspensión de garantias, Madrid, Tecnos, 1984, p. 70.

${ }^{8}$ Sobre esta STC vid. los comentarios de C. GARRIDO LÓPEZ, «Naturaleza jurídica y control jurisdiccional...», op. cit., pp. 43-73, y M. I. ÁLVAREZ VÉLEZ, «Sistema de fuentes del Derecho y estado de alarma: la STC 83/2016, de 28 de abril», Asamblea: revista parlamentaria de la Asamblea de Madrid, núm. 34 (2016), pp. 325-340. 
corresponde, sin duda alguna, al Tribunal Constitucional en ejercicio de sus competencias de control de la constitucionalidad de las leyes y normas con rango de ley», como declaró el mismo al considerar que «aunque formalizada mediante decreto del Consejo de Ministros, la decisión de declarar el estado de alarma, dado su contenido normativo y efectos jurídicos, debe entenderse que queda configurada en nuestro ordenamiento como una decisión o disposición con rango o valor de ley. Y, en consecuencia, queda revestida de un valor normativo equiparable, por su contenido y efectos, al de las leyes y normas asimilables cuya aplicación se puede excepcionar, suspender o modificar durante el estado de alarma» (STC 83/2016, de 28 de abril, FJ 10).

No obstante, en ese fundamento jurídico y en el siguiente se añade: «Lo que se acaba de expresar no excluiría que en aquellas situaciones en las que no se haya producido la dación de cuenta al Congreso o no haya recaído la autorización de prórroga parlamentaria que exige el art. 116.2 $\mathrm{CE}$, la forma de decreto que revista la declaración de alarma pudiera recobrar su relieve a efectos de nuestro control jurisdiccional. Aunque el decreto de declaración de la alarma proceda del Gobierno como órgano constitucional, su control correspondería a esta Sala, como permite el art. 2.a) de la LJCA, respecto de lo que en nuestra jurisprudencia hemos denominado conceptos judicialmente asequibles (por todas, Sentencia de 20 de noviembre de 2013) o sobre los hechos determinantes. La declaración argumentativa de la STC 83/2016 que se ha transcrito no lo impide en cuanto ha sido formulada por el Tribunal Constitucional al resolver un recurso de amparo (STC 83/2016) y no en sede de tribunal de control de constitucionalidad de las leyes».

La falta de jurisdicción sobre decretos de declaración del estado de alarma se refiere únicamente a la norma de declaración y a sus prórrogas, pero no a los decretos o disposiciones que acompañen a dicha declaración o que se dicten durante su vigencia o en relación con la misma (art. 8.2 de la Ley 4/1981, de 1 de junio) ni tampoco respecto de sus actos de aplicación. Así lo dispone en forma expresa el art. 3.1 de la Ley Orgánica 4/1981, de 1 de junio, y lo estableció ya en su momento el Auto de la Sección Séptima de esta Sala de 30 de mayo de 2011, que admitió a trámite el recurso en cuanto se dedujo contra el Real Decreto 1611/2010, de 3 de diciembre, por tratar una actuación con alcance y significación diferente a la declaración del estado de alarma y a la solicitud y autorización de su prórroga. Sobre dicha impugnación recayó posteriormente la Sentencia de 22 de abril de 2015. 
En consecuencia, solo a través del recurso y de la cuestión de inconstitucionalidad (eventualmente de una autocuestión) puede enjuiciarse en términos generales el decreto que declara el estado alarma y sus eventuales prórrogas.

\section{LA DECLARACIÓN DEL ESTADO DE ALARMA POR EL REAL DECRETO 463/2020, DE 14 DE MARZO, «POR EL QUE SE DECLARA EL ESTADO DE ALARMA PARA LA GESTIÓN DE LA SITUACIÓN DE CRISIS SANITARIA OCASIONADA POR EL COVID-19»W, Y LAS SUCESIVAS PRÓRROGAS}

El preámbulo del Decreto 476/2020 incluye el relato gubernamental de la declaración del estado de alarma, de lo acontecido desde su entrada en vigor a través del Decreto 463/2020 y de los motivos que justificarían su prórroga ${ }^{9}$. En la misma línea se inserta, como parece lógico, el preámbu-

9 «La declaración del estado de alarma se extendió a todo el territorio nacional y comprendió las limitaciones a la libertad de circulación de las personas que se consideraron estrictamente indispensables para proteger la salud y la seguridad de los ciudadanos, contener la progresión de la enfermedad y reforzar el sistema de salud pública. En el marco de lo dispuesto por el artículo sexto.dos de la Ley Orgánica 4/1981, de 1 de junio, de los estados de alarma, excepción y sitio, se estableció que la duración del estado de alarma sería de quince días naturales.

Con posterioridad, el Gobierno aprobó el Real Decreto 465/2020, de 17 de marzo, por el que se modificó el Real Decreto 463/2020, de 14 de marzo, con la finalidad de reforzar la protección de la salud pública y de asegurar el funcionamiento de servicios públicos esenciales.

La declaración del estado de alarma ha permitido aplicar medidas inmediatas en los ámbitos contemplados por el Real Decreto 463/2020, de 14 de marzo, que han resultado esenciales para contener la propagación de la enfermedad. Asimismo ha hecho posible establecer, a través de la actuación de las autoridades competentes delegadas del Gobierno, una movilización de todos los recursos disponibles para mitigar los efectos de la pandemia.

Sin embargo, a la luz de los datos disponibles y de los informes de evaluación elaborados por las autoridades competentes, no se puede afirmar que la situación de emergencia sanitaria generada por el Covid-19 se habrá superado completamente en el plazo previsto inicialmente por el Real Decreto 463/2020, de 14 de marzo, por lo que se estima imprescindible prorrogar el estado de alarma declarado en el citado real decreto, así como la vigencia de las medidas en él contenidas, hasta las 00:00 horas del día 12 de abril de 2020...

Mediante Acuerdo del Consejo de Ministros de 24 de marzo de 2020, el Gobierno solicitó del Congreso de los Diputados autorización para prorrogar el estado de alarma declarado mediante Real Decreto 463/2020, de 14 de marzo, con el fin de garantizar la eficaz gestión de la emergencia sanitaria y contener la propagación de la enfermedad.

El Pleno del Congreso de los Diputados, en su sesión del día 25 de marzo de 2020, acordó conceder la autorización requerida, solicitando la inclusión de una nueva disposición adi- 
lo del Decreto $487 / 2020^{10}$, que, por si acaso, ya anticipaba eventuales nuevas prórrogas.

A diferencia de lo que ocurrió con el Decreto 1673/2010, no me ofrece duda alguna que en esta ocasión sí concurren las circunstancias que justifican la adopción del estado de alarma por el Decreto 463/2020 ${ }^{11}$. Tal y como se expone en el preámbulo de esta última norma: «La Organización Mundial de la Salud elevó el pasado 11 de marzo de 2020 la situación de emergencia de salud pública ocasionada por el Covid-19 a pandemia internacional. La rapidez en la evolución de los hechos, a escala nacional e internacional, requiere la adopción de medidas inmediatas y eficaces para hacer frente a esta coyuntura. Las circunstancias extraordinarias que concurren constituyen, sin duda, una crisis sanitaria sin precedentes y de enor-

cional en el Real Decreto 463/2020, de 14 de marzo, que establece la obligación del Gobierno de remitir semanalmente al Congreso información sobre el grado de ejecución de las medidas adoptadas y su eficacia para alcanzar los objetivos propuestos».

${ }^{10}$ «A la luz de la información proporcionada cabe concluir que, durante la vigencia del estado de alarma y su primera prórroga, se han alcanzado los objetivos de asegurar la unidad de acción y movilizar todos los recursos humanos y materiales disponibles para contener la pandemia y mitigar sus efectos [...] Sin embargo, el carácter dinámico y el contexto de elevada incertidumbre que caracteriza la evolución de esta crisis sanitaria mundial sin precedentes obligan a extremar la prudencia. Mientras siga existiendo transmisión, una vuelta a la normalidad podría implicar el inicio de nuevas cadenas de transmisión y un retroceso en los esfuerzos por controlar esta epidemia, lo que además podría mermar la confianza de los ciudadanos. Los modelos desarrollados por los expertos, tanto nacionales como internacionales, muestran que una adecuada gestión de la fase de desescalado de las medidas de control y contención aplicadas resulta crucial para lograr vencer la epidemia.

A esos efectos, la evaluación del riesgo para la vida y la salud de las personas debe realizarse de manera objetiva y transparente, de acuerdo con la mejor evidencia científica disponible. Los análisis realizados a partir de los datos proporcionados por la Red Nacional de Vigilancia Epidemiológica y su modelización permiten concluir que una segunda prórroga contribuirá a reforzar de forma decisiva en todo el territorio nacional la contención de la propagación de la enfermedad para salvar vidas, evitar la saturación de los servicios sanitarios y mantener posibles rebrotes en niveles asumibles por el sistema sanitario. Esta segunda prórroga constituye una medida indispensable para tratar de garantizar que los pacientes que requieran de hospitalización, ingreso en las unidades de cuidados intensivos o ventilación mecánica no superan el umbral que impediría proporcionar la adecuada calidad asistencial en función de los recursos actualmente disponibles. La nueva prórroga se extenderá hasta las 00:00 horas del día 26 de abril de 2020. Solo si se consigue afianzar la evolución favorable detectada en cuanto a los datos de transmisión, número de hospitalizaciones, ingresos en las unidades de cuidados intensivos o decesos, podrá plantearse un escenario en el que puedan ir eliminándose progresivamente las medidas de contención...».

${ }^{11}$ Para una primera aproximación de conjunto vid. el monográfico Coronavirus... y otros problemas, de El Cronista del Estado Social y Democrático de Derecho, núm. 86/87 (2020), disponible en http://www.elcronista.es/El-Cronista-n\%C3\%BAmero-86-87-Coronavirus.pdf (consultado el 14 de mayo de 2020). 
me magnitud tanto por el muy elevado número de ciudadanos afectados como por el extraordinario riesgo para sus derechos.

El artículo cuarto, apartado b), de la Ley Orgánica 4/1981, de 1 de junio, de los estados de alarma, excepción y sitio, habilita al Gobierno para, en el ejercicio de las facultades que le atribuye el art. 116.2 de la Constitución, declarar el estado de alarma, en todo o parte del territorio nacional, cuando se produzcan crisis sanitarias que supongan alteraciones graves de la normalidad».

Nos parece claro que la situación en la que nos encontramos responde a lo previsto en la Ley Orgánica 4/1981 para la declaración del estado de alarma. También, por lo dicho anteriormente en relación con la afectación del orden público, que no se daba el 14 de marzo y no se ha dado con posterioridad el presupuesto que podría justificar la declaración del estado de excepción: ni entonces ni en el momento de concluir estas líneas - 14 de mayo de 2020 - «el libre ejercicio de los derechos y libertades de los ciudadanos, el normal funcionamiento de las instituciones democráticas, el de los servicios públicos esenciales para la comunidad o cualquier otro aspecto del orden público» estuvieron ni están «tan gravemente alterados que el ejercicio de las potestades ordinarias fuera insuficiente para restablecerlo y mantenerlo» (art. 13) ${ }^{12}$.

No entraremos en este breve trabajo en el análisis detallado de diferentes cuestiones constitucionales que se han suscitado desde la declaración del estado de alarma y que ya han generado una abundante y, lógicamente, apresurada literatura jurídica. Sí nos parece oportuno hacer alguna sucinta consideración tanto sobre las medidas que han limitado la libertad de circulación, a las que el Gobierno concedió gran relevancia para «contener la progresión de la enfermedad y reforzar el sistema de salud pública» (preámbulo del Real Decreto 476/2020, de 27 de marzo) ${ }^{13}$, como sobre la primera decisión del Tribunal Constitucional vinculada a la declaración

${ }^{12}$ En un sentido favorable a la declaración del estado de excepción a partir de una comprensión diferente del orden público, vid. F. J. Álvarez García, «Estado de alarma o de excepción», Estudios Penales y Criminológicos, vol. 40 (2020), pp. 1-20.

${ }_{13} \mathrm{Vid}$. los trabajos de los profesores A. NOgueira LÓPEZ, «Confinar el coronavirus. Entre el viejo Derecho sectorial y el Derecho de excepción»; C. Amoedo Souto, «Vigilar y castigar el confinamiento forzoso. Problemas de la potestad sancionadora al servicio del estado de alarma sanitaria», y L. Cotino HuEso, «Los derechos fundamentales en tiempos del coronavirus. Régimen general y garantías y especial atención a las restricciones de excepcionalidad ordinaria», los tres en El Cronista del Estado Social y Democrático de Derecho, núm. 86-87 (2020), pp. 22-31, 66-77 y 88-101, respectivamente, así como el estudio del profesor L. Cotino Hueso, «Confinamientos, libertad de circulación y personal, prohibición de reuniones y actividades y otras restricciones de derechos por la pandemia del coronavirus», 
del estado de alarma (ATC de 30 de abril de 2020) ${ }^{14}$. Ya se ha mencionado en el apartado anterior la reiteración jurisprudencial sobre el control jurisdiccional del decreto de estado de alarma (ATS de 4 de mayo).

Por lo que respecta a las limitaciones, es bien sabido que se concretaron en el ya famoso art. 7 del Real Decreto 463/2020 titulado, precisamente, «Limitación de la libertad de circulación de las personas» y que en su punto 1 dispone: «Durante la vigencia del estado de alarma las personas únicamente podrán circular por las vías o espacios de uso público para la realización de las siguientes actividades, que deberán realizarse individualmente, salvo que se acompañe a personas con discapacidad, menores, mayores o por otra causa justificada: a) adquisición de alimentos, productos farmacéuticos y de primera necesidad; $b$ ) asistencia a centros, servicios y establecimientos sanitarios; c) desplazamiento al lugar de trabajo para efectuar su prestación laboral, profesional o empresarial; $d$ ) retorno al lugar de residencia habitual; $e$ ) asistencia y cuidado a mayores, menores, dependientes, personas con discapacidad o personas especialmente vulnerables; $f$ ) desplazamiento a entidades financieras y de seguros; $g$ ) por causa de fuerza mayor o situación de necesidad; $b$ ) cualquier otra actividad de análoga naturaleza».

La LO 4/1981 parece distinguir entre «limitaciones», propias del estado de alarma, y «prohibiciones», características del estado de excepción. Respecto al primero (art. 11) habla de, entre otras medidas, «a) limitar la circulación o permanencia de personas o vehículos en horas y lugares determinados [...] c) limitar o racionar el uso de servicios o el consumo de artículos de primera necesidad». Respecto del segundo permite, entre otras opciones, «prohibir la circulación de personas y vehículos en las horas y lugares que se determine» (art. 20.1); «prohibir la celebra-

Diario La Ley, núm. 9608 (2020), y el ya citado de F. J. Álvarez GARCía, «Estado de alarma...», op. cit., pp. 1-20.

${ }_{14}$ Adicionalmente cabe señalar que el TC ha admitido, por providencia de 6 de mayo de 2020, el recurso de inconstitucionalidad «promovido por más de cincuenta diputados del Grupo Parlamentario de VOX en el Congreso y, en su representación, por el procurador don Antonio Ortega Fuentes, en relación con los arts. 7, 9, 10 y 11 del Real Decreto $463 / 2020$, de 14 de marzo, por el que se declara el estado de alarma para la gestión de la situación de crisis ocasionada por el Covid-19; Real Decreto 465/2020, de 17 de marzo, en cuanto modifica el art. 7 del Real Decreto 463/2020; Reales Decretos 476/2020, de 27 de marzo; 487/2020, de 10 de abril, y 492/2020, de 24 de abril, en cuanto aprueban sucesivas prórrogas del estado de alarma; Real Decreto 492/2020, además, en cuanto da nueva redacción al art. 7 del Real Decreto 463/2020, y Orden SND/298/2020, de 29 de marzo, por la que se establecen medidas excepcionales en relación con los velatorios y ceremonias fúnebres para limitar la propagación y el contagio por el Covid-19». 
ción de reuniones y manifestaciones» (art. 22.1) y «prohibir las huelgas y la adopción de medidas de conflicto colectivo» (art. 23). Al respecto, el TC ha dicho que «los efectos de la declaración del estado de alarma se proyectan $[\ldots]$ en el establecimiento de determinadas limitaciones o restricciones» (STC 83/2016, FJ 8).

Pues bien, si atendemos a las concretas medidas impuestas con la entrada en vigor del Decreto 463/2020, no parece haber diferencia entre su intensidad y las prohibiciones que serían propias de un estado de excepción tal y como ha articulado la cuestión el legislador orgánico. Estamos, pues, ante una teórica limitación formal de la libertad de circulación que, de hecho, implica una prohibición general de la citada libertad. Y ello parece chocar con la configuración que, como hemos dicho, se dio a la Ley Orgánica 4/1981, en la que el legislador se decantó, pudiendo hacer otra cosa, por una serie de medidas que en el caso del estado de alarma serían menos gravosas que las realmente adoptadas bajo su amparo en el Decreto 463/2020. El juicio de proporcionalidad sobre las mismas (que la medida limitativa sea adecuada o idónea para la consecución del fin perseguido, que sea la mínima imprescindible para tal finalidad y que haya proporcionalidad entre el sacrificio exigido al derecho limitado por esa medida y el concreto derecho, bien o interés que se pretende proteger) no puede hacerse al margen de los propios límites que ha preestablecido el legislador orgánico ${ }^{15}$.

Para resolver estos interrogantes no contamos con jurisprudencia constitucional relevante, pues los casos en los que se interpretó el alcance del art. $19 \mathrm{CE}$ versaron, sobre todo, sobre los derechos de las personas extranjeras para entrar y residir en España. Cabe, no obstante, recordar que, conforme a la STC 94/1993, de 22 de marzo, «las medidas que repercuten sobre la libre circulación de las personas deben fundarse en una Ley y aplicarla en forma razonada y razonable (STC 85/1989, FJ 3)» (FJ 4); que según la STC 72/2005, de 4 de abril, «el art. 19 CE reconoce a "los españoles" cuatro derechos fundamentales distintos: el derecho a elegir libremente su residencia, el derecho a circular por el territorio nacional, el derecho a entrar en España y el derecho a salir libremente del territorio nacional» (FJ 5), y que según la STC 146/2006, de 8 de mayo, «constituye doctrina de este Tribunal que una medida de ese tipo debe sujetarse a parámetros

15 Sobre estas cuestiones vid. P. REQuejo RodrígueZ «La suspensión de los derechos fundamentales», en F. J. BASTIDA FREIEDO et al., Teoría general de los derechos fundamentales en la Constitución española de 1978, Madrid, Tecnos, 2004, pp. 222-235. 
de proporcionalidad en relación con la preservación de otros derechos o bienes constitucionales. Ha de tratarse así de una medida útil y necesaria para la protección de un bien constitucionalmente importante» (FJ 2). Algo que se reitera en la STC 84/2013, de 11 de abril, FJ 6.

Como es obvio, no entramos aquí a valorar si las medidas limitativas de la libertad de circulación pueden ser las mejores para contener la epidemia, al margen de que en otros países no hayan alcanzado la misma intensidad. Pero, además de aplicarse de forma razonada y razonable, «deben fundarse en una Ley» y nos parece discutible, cuando menos, que en el caso que nos ocupa tengan un fundamento claro en la Ley Orgánica 4/1981, máxime teniendo en cuenta la obligación iusfundamental de interpretar la normativa aplicable en el sentido más favorable para la efectividad de los derechos fundamentales (STC 17/1985, de 5 de marzo, FJ 4).

Finalmente, también parece discutible que las medidas limitativas encuentren fundamento en el art. 3 de la Ley Orgánica 3/1986, de 14 de abril, de Medidas Especiales en Materia de Salud Pública, donde se dispone que «(c)on el fin de controlar las enfermedades transmisibles, la autoridad sanitaria, además de realizar las acciones preventivas generales, podrá adoptar las medidas oportunas para el control de los enfermos, de las personas que estén o hayan estado en contacto con los mismos y del medio ambiente inmediato, así como las que se consideren necesarias en caso de riesgo de carácter transmisible».

Apelando a este artículo se avalaron judicialmente las restricciones de movimientos en un hotel de Tenerife cuando el coronavirus apenas había hecho acto ostensible de presencia en España, y la aplicación del citado precepto se justifica, en la resolución judicial, respecto de las personas que «se hallan alojadas o prestando su actividad laboral en un establecimiento hotelero donde se ha detectado la presencia de varias personas portadoras del coronavirus productor de la enfermedad conocida como Covid-19, enfermedad de reciente aparición altamente contagiosa que se transmite de persona a persona» (FJ 3). Más adelante se dice: «Como pone de relieve el Ministerio Fiscal, la ratificación judicial de tales medidas no puede otorgarse de una forma genérica y sin limitación del ámbito personal de afectación». Es decir, el art. 3 se aplica a personas concretas — «los enfermos [y] las personas que estén o hayan estado en contacto con los mismos»- y no de manera general e indiscriminada. Lo que prevé el art. 7 del decreto de estado de alarma es de aplicación general e indiscriminada.

Por lo que respecta a la primera resolución del TC vinculada a la declaración del estado de alarma (Auto de 30 de abril de 2020), tiene especial 
relevancia, pues incide sobre un conflicto jurídico — conflicto en sentido amplio- relacionado con dicha declaración: la eventual lesión del derecho fundamental de reunión (art. $21 \mathrm{CE}$ ) a resultas de la prohibición de «una manifestación rodada en coches particulares en la ciudad de Vigo el viernes día 1 de mayo de 2020, a las 11:00 horas, que tendría comienzo en la Plaza de España, en sustitución de la anteriormente convocada y comunicada a la Subdelegación del Gobierno el pasado 1 de abril» ${ }^{16}$.

Lo primero que llama la atención es que se trata de un auto de inadmisión que se parece mucho en su extensión (los fundamentos jurídicos ocupan quince páginas) y, sobre todo, en sus argumentos, a lo que podría ser una sentencia desestimatoria de un recurso de amparo previamente admitido a trámite.

Es llamativo también que se dediquen cuatro de las quince páginas de los fundamentos a analizar si concurre la exigencia prevista en el art. 50.1.b) de la Ley Orgánica del Tribunal Constitucional (en adelante, LOTC): «Que el contenido del recurso justifique una decisión sobre el fondo por parte del Tribunal Constitucional en razón de su especial trascendencia constitucional».

$\mathrm{Y}$ es llamativo porque, efectivamente, el TC concluye que sí concurre, en concreto, «el supuesto $g$ ) de especial trascendencia constitucional del FJ 2 de la STC 155/2009, porque el supuesto planteado en el recurso de amparo trasciende del caso concreto, ya que plantea una cuestión jurídica de relevante y general repercusión social o económica. No podemos olvidar que, como reconoce la recurrente, la manifestación se pretende desarrollar en el marco de una situación de pandemia global muy grave, que ha producido un gran número de afectados y de fallecidos en nuestro país, y que ha puesto a prueba a las instituciones democráticas y a la propia sociedad y los ciudadanos, en cuanto se han convertido, en conjunto, en elementos esenciales para luchar contra esta situación de crisis sanitaria y económica que afecta a todo el país, situado por mor de la misma ante una situación que, pese a no ser la primera vez que se produce (ya sufri-

${ }^{16}$ En los antecedentes se nos informa que «el motivo de la convocatoria es celebrar el día 1 de mayo, de la clase trabajadora [...]. La manifestación comenzará a las 11:00 en la Plaza de España, indicándose el recorrido, con finalización en Concepción Arenal, delante del edificio de la Xunta a las 12:30 horas». La Subdelegación del Gobierno en Pontevedra respondió, entre otras cosas, «que, en la actualidad, el Real Decreto 463/2020, de 14 de marzo, por el que se declara el estado de alarma para la gestión de la situación de crisis sanitaria ocasionada por el Covid-19, no contempla, entre las actividades excepcionadas de la limitación general para circular, los desplazamientos con el fin expuesto en su comunicación». 
mos, entre otras, la pandemia de 1918), sí es la primera vez que nuestra actual democracia se ha visto en la necesidad de enfrentarse ante un desafío de esta magnitud y de poner en marcha los mecanismos precisos para hacerle frente. Ante esta situación es importante el pronunciamiento de este Tribunal por la repercusión que la celebración de esta o de otras manifestaciones que con ocasión de la señalada fecha del 1 de mayo se puedan pretender celebrar puedan tener sobre el conjunto de la sociedad, especialmente sobre la salud de los ciudadanos, llevando a cabo un análisis de los contenidos del real decreto de declaración del estado de alarma y de su alcance desde la perspectiva constitucional, especialmente en cuanto al ejercicio de los derechos fundamentales, ya que puede establecer pautas importantes en la interpretación y aplicación de las distintas previsiones de aquella norma, en tanto que intérprete supremo de la normal fundamental, que resulten provechosas para el conjunto de la sociedad. Lo que también se puede traducir en la enunciación de criterios de actuación que sean importantes en el desarrollo del proceso de desescalada que está iniciando el Gobierno. Es innegable, en suma, la notoria repercusión que este asunto tiene en el conjunto de la sociedad española» (FJ 2).

Bastaría, en principio, este párrafo para seguir adelante con el recurso y entender que concurre esa especial relevancia constitucional, pero la Sala Primera hace previamente una extensa serie de consideraciones que parecen ajenas a lo que está tratando en esa parte del auto, pues entra a recordar su jurisprudencia no sobre la especial trascendencia constitucional, sino «en relación con el ejercicio de los derechos de reunión y manifestación, a través de la cual este Tribunal ha establecido criterios muy claros en cuanto a los presupuestos para el ejercicio de tales derechos, los límites y restricciones que pueden imponerse a los mismos, especialmente cuando colisionan con otros derechos o con la protección de otros valores constitucionales, así como las garantías que deben presidir tanto su ejercicio como la posibilidad de introducir modificaciones o limitaciones al mismo y, especialmente, cuando se trata de impedirlo». El TC resume a continuación lo dicho en la STC 66/1995, de 8 de mayo, y en las SSTC 301/2006, de 23 de octubre; 170/2008, de 15 de diciembre, y 96/2010, de 15 de noviembre, y todo este arsenal jurisprudencial viene a cuento, «pues de lo que se trata es de identificar ad casum la noción de "orden público" con peligro para las personas, como elemento que ha servido para prohibir la celebración de la manifestación comunicada».

Insisto en que, a mi juicio, toda esta exposición es más bien propia de una sentencia en la que se está analizando si se vulneró un derecho funda- 
mental reclamado en un recurso de amparo admitido a trámite, cosa que, como hemos anticipado, aquí no ocurre. En todo caso, encajaría mejor en el siguiente apartado del auto donde se analiza la eventual adopción de medidas cautelares y la necesidad de una «respuesta inmediata del Tribunal», que acude al Derecho comparado pero, en parte, para apartarse de él: cita la resolución del Tribunal Constitucional Federal Alemán dictada el 15 de abril de 2020 (1 BvR 828/20) antes de concluir que no cabe adoptar una similar (que la autoridad administrativa adopte una nueva resolución que compatibilice el derecho de reunión y la protección de la salud) «porque la manifestación del 1 de mayo, conmemorativa de una determinada efeméride, no puede ser celebrada en otra fecha, de modo que no existe margen temporal que permita devolver el asunto a la autoridad competente para que adopte una decisión diversa».

Sí acoge nuestro TC la doctrina del alemán en otra resolución de 7 de abril para justificar la inviabilidad de adoptar medidas cautelares en este caso, aprovechando para sustentar con ella su decisión de inadmisibilidad.

En la última parte del auto, el TC analiza, en la línea ya dicha de una sentencia desestimatoria, «la eventual lesión del derecho fundamental invocado (derecho de manifestación del art. $21 \mathrm{CE}$ )». Y comienza recordando que «para que los poderes públicos puedan incidir en el derecho de reunión constitucionalmente garantizado, ya sea restringiéndolo, modificando las circunstancias de su ejercicio o prohibiéndolo incluso, es preciso [...] que existan razones fundadas, lo que implica una exigencia de motivación de la resolución correspondiente». El TC admite que la resolución de la Subdelegación del Gobierno «es abiertamente ambigua y ni siquiera deja totalmente clara la prohibición, [pero] no puede negarse que existe motivación suficiente en la Sentencia de la Sección 1. ${ }^{a}$ de la Sala de lo Contencioso Administrativo del Tribunal Superior de Justicia de Galicia de 28 de abril de 2020. Cualquier defecto de motivación de la resolución administrativa, por tanto, habría quedado subsanado por la extensa motivación del órgano judicial».

A continuación, el TC declara que «la discusión sobre si el decreto de declaración del estado de alarma supone o no, de facto y por derivación de la limitación de la libertad deambulatoria del art. 19 CE, una limitación excesiva o incluso una suspensión del derecho de manifestación no puede ser abordada, ni siquiera a efectos dialécticos en este momento procesal, ni siquiera en este recurso de amparo».

Aquí el TC da otra puntada a su hilo argumental y parece esbozar algo parecido a un aviso para navegantes-recurrentes del decreto del estado 
de alarma, pues, como prevé el art. 55.2 LOTC, «si el recurso de amparo debiera ser estimado porque, a juicio de la Sala, la ley [en nuestro caso el Decreto 463/2020 que acordó el estado de alarma] aplicada lesione derechos fundamentales o libertades públicas, se elevará la cuestión al Pleno con suspensión del plazo para dictar sentencia, de conformidad con lo previsto en los arts. 35 y siguientes».

En suma, el TC deja de lado el Decreto 463/2020, en particular su art. 7, y pasa a estudiar si la prohibición de la manifestación encaja en el art. $21 \mathrm{CE}$. Y lo hace remitiéndose, textualmente, a una constante jurisprudencia constitucional, a la que ya hemos hecho referencia extensa en el FJ 2, sobre el carácter limitado de los derechos fundamentales en general y de la libertad de reunión en particular.

Pero en lugar de seguir con la interpretación del art. 21, especialmente con la parte que alude a la prohibición de reuniones «cuando existan razones fundadas de alteración del orden público, con peligro para personas o bienes», el TC acude a los arts. 15 (derecho a la vida y a la integridad física) y 43 CE (derecho a la salud) y nos dice que «en el estado actual de la investigación científica, cuyos avances son cambiantes con la evolución de los días, incluso de las horas, no es posible tener ninguna certeza sobre las formas de contagio ni sobre el impacto real de la propagación del virus, así como no existen certezas científicas sobre las consecuencias a medio y largo plazo para la salud de las personas que se han visto afectadas en mayor o menor medida por este virus. Ante esta incertidumbre tan acentuada y difícil de calibrar desde parámetros jurídicos que acostumbran a basarse en la seguridad jurídica que recoge el art. 9.3 de la Constitución, las medidas de distanciamiento social, confinamiento domiciliario y limitación extrema de los contactos y actividades grupales son las únicas que se han adverado eficaces para limitar los efectos de una pandemia de dimensiones desconocidas hasta la fecha. Desconocidas y, desde luego, imprevisibles cuando el legislador articuló la declaración de los estados excepcionales en el año 1981. En todo caso, parece obvio que la prohibición de celebrar la manifestación, que se deriva claramente de la resolución judicial impugnada, guarda una relación lógica y de necesidad evidente con la finalidad perseguida por esa misma interdicción: evitar la propagación de una enfermedad grave, cuyo contagio masivo puede llevar al colapso de los servicios públicos de asistencia sanitaria. La adecuación entre la finalidad pretendida por la limitación y la herramienta jurídica empleada en este caso no parece, por tanto, inexistente».

El TC, en su juicio de proporcionalidad de la medida prohibitiva sobre el que enseguida volveremos, añade que «no se prevén por los organizado- 
res medidas de control de la transmisión del virus específicas ni destinadas a compensar la previsible concentración de automóviles que podría producirse si existiera una masiva respuesta a la convocatoria», que «el itinerario elegido por los convocantes supone ocupar durante varias horas [en teoría hora y media] la vía principal de circulación automovilística en Vigo, dividiendo la ciudad en dos y, eventualmente, limitando el acceso a los hospitales que se encuentran en la zona alta de la ciudad de las personas que viven en la zona más cercana a la costa» y, más abajo, que «el impacto de la infección del Covid-19 en la ciudad de Vigo tampoco es un dato despreciable a la hora de formular el juicio de proporcionalidad que nos planteamos».

En relación con estas argumentaciones cabe, si no objetar, sí, cuando menos, precisar lo siguiente: los promotores ofrecen una modalidad de manifestación que puede ser discutible, pero, según la Ley Orgánica 9/1983, de 15 de julio, reguladora del derecho de reunión, «si la autoridad gubernativa considerase que existen razones fundadas de que puedan producirse alteraciones del orden público, con peligro para personas o bienes, podrá prohibir la reunión o manifestación o, en su caso, proponer la modificación de la fecha, lugar, duración o itinerario de la reunión o manifestación» (art. 10), es decir, si la Subdelegación del Gobierno en Pontevedra considera que las propuestas de los organizadores son insuficientes puede proponer medidas que las complementen (por ejemplo, que la manifestación dure media hora y no hora y media o que el recorrido sea distinto y no limite el acceso a los hospitales); sin embargo, la autoridad administrativa no hace ningún esfuerzo por tratar de hacer efectivo un derecho tan relevante como el de reunión en una fecha tan importante como la del 1 de mayo. Y eso que la entidad convocante se había mostrado abierta a adoptar más medidas ${ }^{17}$.

$\mathrm{Al}$ respecto, hay que recordar que la prohibición constituye, como es lógico si partimos del principio de efectividad de los derechos fundamentales, el «último recurso», debiendo antes contemplarse, como prevé la Ley Orgánica 9/1983, la opción de proponer a los promotores modificaciones que puedan hacer compatible el derecho de reunión con otros derechos, en la línea, por ejemplo, de lo resuelto por la sentencia del Tribunal Superior de Justicia de Aragón, que anuló la decisión de la Delegación del Gobierno en Zaragoza que prohibía una manifestación similar a la de Pontevedra, resolviendo que «deberá estar limitada a la participación de sesen-

17 Así, en el punto sexto de la convocatoria se decía que, «entendendo a gravidade da situación que vivimos a CUT opta po la manifestación rodada cun manifestante en cada auto e debidamente protexidos e identificados polo sindicato, e atendendo a calquera outra indicación que se nos faga dende esta subdelegacion ou as autoridades sanitarias». 
ta ciudadanos, en vehículo particular, cubierto, turismo, con un único ocupante en cada uno, sin que sea admisible la participación en otro tipo de vehículo no cubierto, esto es, motocicleta o bicicleta, por la posibilidad de contagio al exterior».

Pero es que el propio TC en su auto de inadmisión no hace un auténtico juicio de proporcionalidad sobre la medida adoptada por la Subdelegación del Gobierno y avalada por el TSJ de Galicia tal y como el mismo lo ha configurado: «En primer lugar, que sea idónea para alcanzar el fin constitucionalmente legítimo perseguido por ella [...]; en segundo lugar, que sea necesaria o imprescindible para ello, esto es, que no existan otras medidas menos gravosas que, sin imponer sacrificio alguno de derechos fundamentales o con un sacrificio menor, sean igualmente aptas para dicho fin (juicio de necesidad), y, por último, que se deriven de su aplicación más beneficios o ventajas para el interés general que perjuicios sobre otros bienes o intereses en conflicto, o, dicho de otro modo, que el sacrificio impuesto al derecho fundamental no resulte desmedido en relación con la gravedad de los hechos y las sospechas existentes (juicio de proporcionalidad en sentido estricto)» (por ejemplo, STC 70/2002, de 3 de abril, FJ 10).

En el caso que nos ocupa, el TC parece obviar las dos primeras exigencias de este principio y va directamente a la tercera: sin duda la protección de la vida, de la salud y del funcionamiento del sistema sanitario son más relevantes para el interés general que la prohibición de una concreta manifestación, pero ¿es la prohibición de una manifestación que se celebrará a bordo de vehículos, en el contexto de concentraciones de personas en centros de trabajo y en supermercados, la media adecuada para esa finalidad? Y, sobre todo, ¿es la prohibición la medida mínima imprescindible en el sentido de que no haya otra que con un sacrificio menor sea apta para el mismo fin?

\section{BREVÍSIMO EPÍLOGO: LA NECESARIA REFLEXIÓN SOBRE EL ESTADO DE ALARMA EN LA SOCIEDAD DEL RIESGO GLOBAL}

En el bien conocido libro de Ulrich Beck, La sociedad del riesgo. Hacia una nueva modernidad ${ }^{18}$, que poco más tarde se convirtió en La sociedad

${ }^{18}$ U. BeCK, Risikogesellschaft. Auf dem Weg in eine andere Moderne, Frankfurt, Suhrkamp, 1986 (edición española: La sociedad del riesgo. Hacia una nueva modernidad, Madrid, Paidós, 1998). 
del riesgo global ${ }^{19}$, se alude a la sociedad en la que vivimos con unas palabras que, escritas en 1986, no parecen haber perdido un ápice de vigencia casi treinta y cinco años después: en la disputa pública sobre la definición de los riesgos se trata «no solo de las consecuencias para la salud de la naturaleza y del ser humano, sino de los efectos secundarios sociales, económicos y políticos [...]: hundimiento de mercados [...], controles burocráticos de las decisiones empresariales, apertura de nuevos mercados, costes monstruosos, procedimientos judiciales. En la sociedad del riesgo surge así a impulsos pequeños y grandes el potencial político de las catástrofes. La defensa y administración de las mismas pueden incluir una reorganización del poder y de la competencia. La sociedad del riesgo es una sociedad catastrófica. En ella, el estado de excepción amenaza con convertirse en el estado de normalidad» $\gg^{20}$ (cursivas en el original).

Pues bien, lo que estamos viviendo con la epidemia de coronavirus muestra con toda su crudeza no solo su efecto devastador sobre la salud y la vida de miles de personas, sino también los efectos «secundarios» sociales, económicos y políticos: todavía más empobrecimiento y exclusión para las personas más vulnerables, probable pérdida de cientos de miles de puestos de trabajo, puesta en cuestión de las instituciones políticas por su incapacidad para prever y hacer frente de manera eficaz a riesgos que quizá no se vean venir con mucha antelación, pero de los que se debe responder...

Por todo ello es necesario que cuando se recupere cierto «estado de normalidad» tenga lugar una intensa reflexión política y social sobre la mejor forma de responder a los riesgos inherentes a esta sociedad «catastrófica» en la que vivimos. Y el derecho de la excepción en sentido amplio, incluido el propio de lo que aquí hemos llamado estado de alarma, no solo no debe sustraerse a esa discusión, sino que debe ser uno de los aspectos importantes de un debate en el que siempre debe estar presente el objetivo, mencionado en el preámbulo de nuestra Constitución, de «establecer una sociedad democrática avanzada».

${ }^{19}$ U. BECK, La sociedad del riesgo global, Madrid, Siglo XXI, 2002.

${ }^{20}$ Ibid., p. 30. 


\section{REFERENCIAS BIBLIOGRÁFICAS}

Aba Catoira, A.: «El estado de alarma en España», Teoría y Realidad Constitucional, núm. 28 (2011), pp. 305-334.

Álvarez García, F. J.: «Estado de alarma o de excepción», Estudios Penales y Criminológicos, vol. 40 (2020), pp. 1-20.

Álvarez Vélez, M. I.: «Sistema de fuentes del Derecho y estado de alarma: la STC 83/2016, de 28 de abril», Asamblea: revista parlamentaria de la Asamblea de Madrid, núm. 34 (2016), pp. 325-340.

Amoedo Souto, C.: «Vigilar y castigar el confinamiento forzoso. Problemas de la potestad sancionadora al servicio del estado de alarma sanitaria», El Cronista del Estado Social y Democrático de Derecho, núm. 86-87 (2020), pp. 66-77.

BECK, U.: Risikogesellschaft. Auf dem Weg in eine andere Moderne, Frankfurt, Suhrkamp, 1986.

- La sociedad del riesgo. Hacia una nueva modernidad, Madrid, Paidós, 1998.

- La sociedad del riesgo global, Madrid, Siglo XXI, 2002.

Carro Martínez, A.: «Art. 116. Situaciones de anormalidad constitucional», en Ó. Alzaga Villamil (dir.), Comentarios a la Constitución española de 1978, Madrid, Edersa, 1998, pp. 210 y ss.

Cotino Hueso, L.: «Los derechos fundamentales en tiempos del coronavirus. Régimen general y garantías y especial atención a las restricciones de excepcionalidad ordinaria», El Cronista del Estado Social y Democrático de Derecho, núm. 86-87 (2020), pp. 88-101.

— «Confinamientos, libertad de circulación y personal, prohibición de reuniones y actividades y otras restricciones de derechos por la pandemia del coronavirus», Diario La Ley, núm. 9608 (2020).

Cruz Villalón, P.: «El nuevo derecho de excepción (Ley Orgánica 4/1981, de 1 de junio)», Revista Española de Derecho Constitucional, núm. 2 (1981), pp. 93-128.

- Estados excepcionales y suspensión de garantías, Madrid, Tecnos, 1984.

Enérez OlaecheA, F. J.: «La declaración del estado de alarma para la normalización del transporte aéreo», Revista Aranzadi Doctrinal, núm. 6 (2011), pp. 79-94.

FERnÁNDEZ Segado, F.: «La ley orgánica de los estados de alarma, excepción y sitio», Revista de Derecho Político, núm. 11 (1981), pp. 83-116.

GARRIDO LÓPEz, C.: «Naturaleza jurídica y control jurisdiccional de las decisiones constitucionales de excepción», Revista Española de Derecho Constitucional, núm. 110 (2017), pp. 43-73.

López Garrido, D.: Estados de alarma, excepción y sitio. Trabajos parlamentarios, Madrid, Cortes Generales, 1984. 
Nogueira López, A.: «Confinar el coronavirus. Entre el viejo Derecho sectorial y el Derecho de excepción», El Cronista del Estado Social y Democrático de Derecho, núm. 86-87 (2020), pp. 22-31.

Pérez Sola, N.: «Los estados de alarma, excepción y sitio: la primera declaración del estado de alarma en aplicación de las previsiones constitucionales», en Constitución y democracia. Ayer y boy: libro homenaje a Antonio Torres del Moral, vol. 2, Madrid, Universitas, 2012, pp. 1539-1556.

Presno Linera, M. A.: «Estado de alarma por coronavirus y protección jurídica de los grupos vulnerables», El Cronista del Estado Social y Democrático de Derecho, núm. 86-87 (2020), pp. 54-65.

- «Coronavirus SARS-CoV-2, garantía de derechos fundamentales y límites a los mismos en el Derecho español», en BLJ 2/20: Instant Forum-Diritto, dirittied emergenza ai tempi del Coronavirus, 2020, disponible en https://www.biodiritto.org/ Online-First-BLJ/Online-First-BLJ-2-20-Instant-Forum-Diritto-diritti-ed-emergenza -ai-tempi-del-Coronavirus.

— «Estado de alarma y sociedad del riesgo global», en J. F. Rodríguez Ayuso y E. Atienza Macías (coords.), Las respuestas del Derecho a las crisis de salud pública, Madrid, Dykinson, 2020, pp. 15-28.

Requejo Rodríguez, P.: «¿Suspensión o supresión de los derechos fundamentales?», Revista de Derecho Político, núm. 51 (2001), pp. 105-138.

- «La suspensión de los derechos fundamentales», en F. J. Bastida Freijedo et al., Teoría general de los derechos fundamentales en la Constitución española de 1978, Madrid, Tecnos, 2004, pp. 222-235.

- «Art. 55. De la suspensión de los derechos y libertades», en M. E. Casas BaAmonde y M. Rodríguez-Piñero y Bravo Ferrer (dirs.), Comentarios a la Constitución española. XXX aniversario, Madrid, Wolters Kluwer, 2009, pp. 1201 y ss.

- «Teoría y práctica del estado de alarma en España», en Constitución y democracia. Ayer y boy: libro bomenaje a Antonio Torres del Moral, vol. 2, Madrid, Universitas, 2012, pp. 1499-1514.

Torres Muro, I.: «Art. 116. Los estados excepcionales», en M. E. Casas BAamonDe, y M. Rodríguez-Piñero y Bravo Ferrer (dirs.), Comentarios a la Constitución española. XXX aniversario, Madrid, Wolters Kluwer, 2009, pp. 1814 y ss.

Vidal Prado, C., y Delgado Ramos, D.: «Algunas consideraciones sobre la declaración del estado de alarma y su prórroga», Revista Española de Derecho Constitucional, núm. 92 (2011), pp. 244 y ss. 